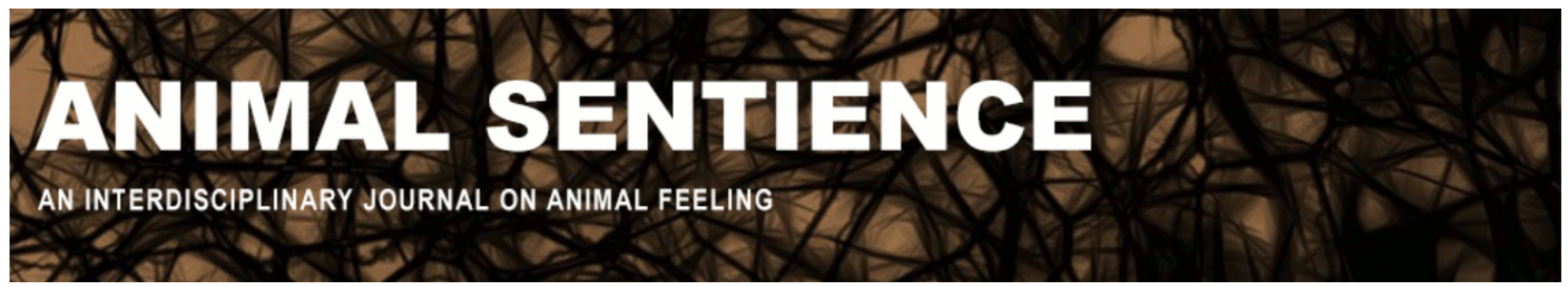

Baluška, František (2016) Should fish feel pain? A plant perspective. Animal Sentience 3(16)

DOI: $10.51291 / 2377-7478.1052$

Date of submission: $2015-10-29$

Date of acceptance: 2015-12-13

(c)

This article has appeared in the journal Animal

Sentience, a peer-reviewed journal on animal

cognition and feeling. It has been made open access,

free for all, by WellBeing International and deposited

in the WBI Studies Repository. For more information,

please contact

wbisr-info@wellbeingintl.org.

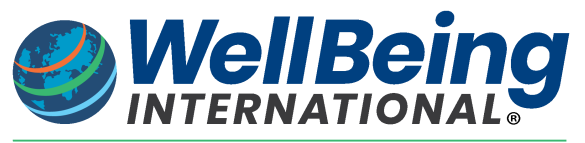

SOLUTIONS FOR PEOPLE, ANIMALS AND ENVIRONMENT 


\title{
Should fish feel pain? A plant perspective
}

Commentary on Key on Fish Pain

\author{
František Baluška \\ Institute of Cellular and Molecular Biology \\ University of Bonn
}

\begin{abstract}
Key (2016) claims fish that fish do not feel pain because they lack the necessary neuronal architecture: their responses to noxious stimuli, according to Key, are executed automatically without any feelings. However, as pointed out by many of his commentators, this conclusion is not convincing. Plants might provide some clues. Plants are not usually thought to be very active behaviorally, but the evidence suggests otherwise. Moreover, in stressful situations, plants produce numerous chemicals that have painkilling and anesthetic properties. Finally, plants, when treated with anesthetics, cannot execute active behaviors such as touch-induced leaf movements or rapid trap closures after localizing animal prey.
\end{abstract}

František Baluška baluska@uni-bonn.de does research on plant signaling, plant behavior, and evolution of the eukaryotic cell at IZMB, University of Bonn. He founded the journals Plant Signaling \& Behavior and Communicative \& Integrative Biology, and he edits the book series Signaling and Communication in Plants. http://ds9.botanik.uni-bonn.de/zellbio/AG-Baluska-Volkmann/

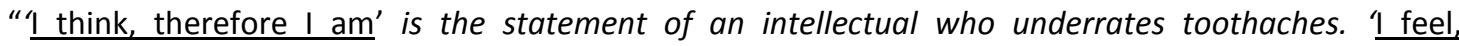
therefore I am' is a truth much more universally valid, and it applies to everything that's alive....[W]hen someone steps on my foot, only I feel the pain. The basis of the self is not thought but suffering, which is the most fundamental of all feelings." - Milan Kundera, Immortality (1988)

Although plants are generally considered passive automata-like organisms, recent research reveals very rich behavior in plants supported by complex electrophysiology with neuron-like cellular and molecular features (Baluška 2010; Baluška and Mancuso 2009a,b; Baluška et al. 2004, 2005, 2006; Brenner et al. 2006). Moreover, plants have also been interpreted as exhibiting their own plant-specific cognition, intelligence, and behavior (Trewavas 2005, 2009, 2014; Trewavas and Baluška 2011; Calvo and Baluška 2015). Plants communicate using a very rich repertoire of volatile chemicals, they manipulate insects and some animals for their own benefit, and some plants such as orchids even show deceptive behavior (Schiestl 2005). All plants use their plant-specific sensory systems to obtain faithful information about the environment and apply their specific problem-solving strategies and behavior to coping with and surviving these stressful situations (Baluška et al. 2006; Trewavas 2005, 2009, 2014; Trewavas and Baluška 2011; Calvo and Baluška 2015).

As Sneddon \& Leach (2016) suggest in their commentary on Key (2016), the denial of fish pain is linked to anthropomorphic views that are not supported by experimental evidence. In fact, because of the subjective nature of pain (and of all other feelings), it is not possible to draw any strong conclusions in this respect. We can, however, make indirect inferences on the basis of many measurable parameters, including molecular ones. For example, plants are 
known to produce numerous substances that are known to have pain-relieving and mindaltering properties (Kennedy and Wightman 2011; Kennedy 2014). Current thinking is that these substances aid plants in their fight against herbivores. This might be the case with the mind-altering and cognition-enhancing substances, but surely not the pain-relieving ones. It is not in the plant's adaptive interest to invest energy to synthesize these expensive substances just to please animals or humans. It seems more plausible to assume that plants synthesize these substances for their own benefit - especially when the synthesis occurs under conditions of injury or stress.

According to contemporary botany, ethylene is a stress-response hormone in plants (Müller and Munné-Bosch 2015; Yang et al. 2015). Ethylene is also a powerful general anesthetic in animals (Dillard 1930; Campagna et al. 2003). Chauncey Leake synthesized divinyl ether from ethylene to enhance its anesthetic properties (Finer 1965; Mazurek 2007). Stressed plants endogenously produce not only ethylene, but also divinyl ether (Itoh and Howe 2001; Stumpe et al. 2008; Fammartino et al. 2010). Bacteria, fungi, algae and lichens too are known to produce ethylene under stress (Lynch and Harper 1974; Primrose and Dilworth 1976; Chagué et al. 2002). This suggests that ethylene plays a fundamental adaptive role in all living organisms.

A parallel example is caffeine and nectar, which are synthesized by plants for the benefit (to the plant) of their effects on animals, rather then any direct effect on the plants themselves. Recent studies suggest that - for their own benefit - plants add caffeine to their nectar to enhance their pollinators' memory and cognition (Wright et al. 2013; Chittka and Peng 2013; Couvillon et al. 2015). Plants also increase the attractiveness of their nectar with other substances that support pollinator health (Richardson et al. 2015). There are several specific examples of chemical manipulation of ants by plants, for the benefit of plants (Grasso et al. 2015; Heil 2015). It is even beginning to be thought that the evolution of the human brain, too, might have been influenced by plant chemistry (Kennedy and Wightman 2011; Kennedy 2014). Interestingly, fruits - which flowering plants designed in their evolution as their organs to be eaten by animals/humans - ripen (i.e., become attractive via their special tastes, aromas, nutritive and health-relevant values, colors and shapes) under the actions of ethylene (Chaves and de Mello-Farias 2006; Barry and Giovannoni 2007). In some plants, unripe fruits can even be poisonous, suggesting that plants can actively prevent consumption of such unripe fruits via toxic chemicals (Lev-Yadun et al. 2009). Similarly, toxic nectar deters possible nectar thieves (Stephenson 1981).

Of course, it would be very difficult to prove that pain-relieving and anesthetic substances are relieving pain in plants themselves. But there have been very relevant findings concerning the neuronal roles of neurotransmitters in plants. Plants synthesize almost all known neurotransmitters. It was formerly assumed that in plants these substances do not play a role in signaling and cell-cell communication anything like the role they play in animal brains. This view has been changing dramatically in recent years. Glutamate signaling is now well recognized in plants. Recent studies have shown that the chemistry and actions of glutamate receptors are similar in plants and animals (Forde 2014; Weiland et al. 2016). GABA receptors have likewise been found recently in plants (Ramesh et al. 2015; Žárský 2015). Neuron-like GABA and glutamate signaling controls (at least) root growth and behavior as well as plant 
sexual reproduction (Forde 2014; Biancucci et al. 2015; Ramesh et al. 2015; Žárský 2015; Weiland et al. 2016).

Plant roots are very active organs, searching for mineral nutrients and water in the darkness of an underground environment. Their apices are equipped with a sensory root cap and neuron-like transition zones with numerous neuron-like features (Baluška et al. 2004, 2009; Baluška and Mancuso 2013). Recent studies reveal that roots show preferences and negative responses in their growth patterns (Yokawa et al. 2014a). They avoid or escape vigorously if exposed to light or dangerous salt stress areas (Burbach et al. 2012; Yokawa et al. 2011, 2014a, 2014b; Yokawa and Baluška 2015). This phenomenon opens the possibility that plant roots could have a plant-specific version of negative feelings that help them avoid or escape dangerous situations. This should perhaps not be surprising in view of the fact that all organisms need to be able to recognize danger and perform a proper response to minimize the negative effects of injury or stress.

So, do plants have something like plant-specific consciousness? Of course it is impossible to draw any strong conclusions on this question. But, as with the neuron-like chemistry and the synthesis of mind-altering substances discussed above, indirect evidence does suggest the possibility of such a phenomenon in plants (Trewavas and Baluška 2011). The endogenous production of anesthetics like ethylene and ethyl-ether, and of numerous substances that have pain-killing properties in humans and animals, especially when stressed, is compatible with the possibility of some plant-specific form of pain or negative experience. Indeed, plants are also sensitive to exogenous anesthetics (Bernard 1878; Grémiaux et al. 2014), even to manmade compounds that plants never encountered in their evolution, such as xenon, halothane, ketamine and lidocaine (Milne and Beamish 1999; De Luccia 2012). The touch-induced closing of Mimosa leaves and the snapping of Dionea and Drosera traps are blocked if these plants are treated with exogenous anesthetics. Whatever it is that is switched off and on by adding or removing these compounds, it is also present in plants. Already in 1878, Claude Bernard stated that "what is alive must sense and can be anesthetized, the rest is dead." He thereby proposed sensitivity to anesthetics as a prime criterion of life (Bernard 1878; Grémiaux et al. 2014).

The perception of negative or stressful conditions through pain-like states - and consciousness itself - may be essential for any organism to be able to navigate in the complex and often dangerous physical environment. This internal, subjective compass (as represented by pain) and the ability to process and act upon it (via consciousness) may be what allowed the survival and evolution of organisms on Earth. 


\section{References}

Baluška, F. (2010). Recent surprising similarities between plant cells and neurons. Plant Signaling \& Behavior 5, 87-89.

Baluška, F. \& Mancuso, S. (2009a). Plant neurobiology: From stimulus perception to adaptive behavior of plants, via integrated chemical and electrical signaling. Plant Signaling \& Behavior 4, 475-476.

Baluška, F. \& Mancuso, S. (2009b). Plant neurobiology: from sensory biology, via plant communication, to social plant behaviour. Cognitive Processing 10(Suppl. 1), 3-7.

Baluška, F. \& Mancuso, S. (2013). Root apex transition zone as oscillatory zone. Frontiers in Plant Science 4, 354.

Baluška, F., Mancuso, S., Volkmann, D. \& Barlow, P.W. (2004). Root apices as plant command centres: the unique 'brain-like' status of the root apex transition zone. Biologia 59 (Suppl. 13), 9-17.

Baluška, F., Mancuso, S., Volkmann, D. \& Barlow, P.W. (2009). The 'root-brain' hypothesis of Charles and Francis Darwin: Revival after more than 125 years. Plant Signaling \& Behavior 4, 1121-1127.

Baluška, F., Volkmann, D. \& Mancuso, S. (Eds.) (2006). Communication in Plants: Neuronal Aspects of Plant Life. Springer Verlag.

Baluška, F., Volkmann, D. \& Menzel, D. (2005). Plant synapses: actin-based adhesion domains for cell-to-cell communication. Trends in Plant Science 10, 106-111.

Barry, C.S. \& Giovannoni, J.J. (2007). Ethylene and fruit ripening. Journal of Plant Growth Regulation 26, 143-159.

Bernard, C. (1878). Leçons sur les phénomènes de la vie communs aux animaux et aux végétaux. Lectures on Phenomena of Life Common to Animals and Plants. Paris, Ballliere, and Son.

Biancucci, M., Mattioli, R., Forlani, G., Funck, D., Costantino, P. \& Trovato, M. (2015). Role of proline and GABA in sexual reproduction of angiosperms. Frontiers in Plant Science 6, 680.

Brenner, E. D., Stahlberg, R., Mancuso, S., Vivanco, J., Baluška, F. \& Van Volkenburgh, E. (2006). Plant neurobiology: an integrated view of plant signaling. Trends in Plant Science 11, 413419.

Burbach, C., Markus, K., Yin, Z., Schlicht, M. \& Baluška, F. (2012). Photophobic behaviour of maize roots. Plant Signaling \& Behavior 7, 876-880. 
Calvo, P. \& Baluška, F. (2015). Conditions for minimal intelligence across eukaryota: a cognitive science perspective. Frontiers in Psychology 6, 1329.

Campagna, J.A., Miller, K.W. \& Forman, S.A. (2003). Mechanisms of actions of inhaled anesthetics. New England Journal of Medicine 348, 2110-2124.

Chagué, V., Elad, Y., Barakat, R., Tudzynski, P. \& Sharon, A. (2002). Ethylene biosynthesis in Botrytis cinerea. FEMS Microbiology Ecology 40, 143-149.

Chaves, A.L.S. \& de Mello-Farias, P.C. (2006). Ethylene and fruit ripening: from illumination gas to the control of gene expression, more than a century of discoveries. Genetics and Molecular Biology 29, 508-515.

Chittka, L. \& Peng, F. (2013). Caffeine boosts bees' memories. Science 339, 1157-1159.

Couvillon, M.J., Al Toufailia, H., Butterfield, T.M., Schrell, F., Ratnieks, F.L. \& Schürch, R. (2015). Caffeinated forage tricks honeybees into increasing foraging and recruitment behaviors. Current Biology 25, 2815-2818.

De Luccia, T.P. (2012). Mimosa pudica, Dionaea muscipula and anesthetics. Plant Signaling \& Behavior 7, 1163-1167.

Dillard, M.M. (1930). Ethylene - the new general anesthetic. Journal of National Medical Association 22, 10-11.

Fammartino, A., Verdaguer, B., Fournier, J., Tamietti, G., Carbonne, F., Esquerré-Tugayé, M.T. \& Cardinale, F. (2010). Coordinated transcriptional regulation of the divinyl ether biosynthetic genes in tobacco by signal molecules related to defense. Plant Physiology and Biochemistry 48, 225-231.

Finer, B. (1965). Divinyl ether. British Journal of Anaesthesilogy 37, 661-666.

Forde, B.G. (2014). Glutamate signalling in roots. Journal of Experimental Botany 65, 779-787.

Grasso, D.A., Pandolfi, C., Bazihizina, N., Nocentini, D., Nepi, M. \& Mancuso, S. (2015). Extrafloral-nectar-based partner manipulation in plant-ant relationships. AoB Plants 7 , plv002.

Grémiaux, A., Yokawa, K., Mancuso, S. \& Baluška, F. (2014). Plant anesthesia supports similarities between animals and plants: Claude Bernard's forgotten studies. Plant Signaling \& Behavior 9, e27886.

Heil, M. (2015). Extrafloral nectar at the plant-insect interface: a spotlight on chemical ecology, phenotypic plasticity, and food webs. Annual Reviews of Entomology 60, 213232. 
Itoh, A. \& Howe, G.A. (2001). Molecular cloning of a divinyl ether synthase. Journal of Biological Chemistry 276, 3620-3627.

Kennedy, D.O. (2014). Plants and the Human Brain. Oxford University Press.

Kennedy, D.O. \& Wightman, E.L. (2011). Herbal extracts and phytochemicals: plant secondary metabolites and the enhancement of human brain function. Advances in Nutrition 2, 3250 .

Key, B. (2016). Why fish do not feel pain. Animal Sentience 2016.003.

Kundera, M. (1988/99) Immortality. Harper Collins.

Lev-Yadun, S., Ne'eman, G. \& Izhaki, I. (2009). Unripe red fruits may be aposematic. Plant Signaling \& Behavior 4, 836-841.

Lynch, J.M. \& Harper, S.H.T. (1974). Formation of ethylene by a soil fungus. Journal of General Microbiology 80, 187-195.

Mazurek, M.J. (2007). Chauncey Leake and the development of divinyl oxide from bench to bedside. CSA Bulletin 2007, 6-9.

Milne, A. \& Beamish, T. (1999). Inhalational and local anesthetics reduce tactile and thermal responses in mimosa pudica. Canadian Journal of Anesthesia 46, 287-289.

Müller, M. \& Munné-Bosch, S. (2015). Ethylene Response Factors: a key regulatory hub in hormone and stress signaling. Plant Physiology 169, 32-41.

Primrose, S.B. \& Dilworth, M.J. (1976). Ethylene production by bacteria. Journal of General Microbiology 93, 177-181.

Ramesh, S.A., Tyerman, S.D., Xu, B., Bose, J., Kaur, S., Conn, V., Domingos, P., Ullah, S., Wege, S., Shabala, S., Feijó, J.A., Ryan, P.R. \& Gillham, M. (2015). GABA signalling modulates plant growth by directly regulating the activity of plant-specific anion transporters. Nature Communications 6, 7879.

Richardson, L.F., Adler, L.S., Leonard, A.S., Andicoechea, J., Regan, K.H., Anthony, W.E., Manson, J.S. \& Irwin, R.E. (2015). Secondary metabolites in floral nectar reduce parasite infections in bumblebees. Proceedings of Royal Society B 282, 20142471.

Schiestl, F.P. (2005). On the success of a swindle: pollination by deception in orchids. Naturwissenschaften 92, 255-264.

Sneddon, L.U. \& Leach, M.C. (2016). Antropomorphic denial of fish pain. Animal Sentience 2016.035.

Stephenson, A.G. (1981). Toxic nectar deters nectar thieves of Catalpa speciosa. American Midland Naturalist 105, 381-383. 
Stumpe, M., Carsjens, J.G., Göbel, C. \& Feussner, I. (2008). Divinyl ether synthesis in garlic bulbs. Journal of Experimental Botany 59, 907-915.

Trewavas, A. (2005). Plant intelligence. Naturwissenschaften 92, 401-413.

Trewavas, A. (2009). What is plant behaviour? Plant Cell Environment 32, 606-616.

Trewavas, A. (2014). Plant Behaviour and Intelligence. Oxford University Press.

Trewavas, A. \& Baluška, F. (2011). The ubiquity of conciosusness. The ubiquity of conciosusness, cognition and intelligence in life. EMBO Reports 12, 1221-1225.

Weiland, M., Mancuso, S. \& Baluška, F. (2016). Signalling via glutamate and GLRs in Arabidopsis thaliana. Functional Plant Biology, In press.

Wright, G.A., Baker, D.D., Palmer, M.J., Stabler, D., Mustard, J.A., Power, E.F., Borland, A.M. \& Stevenson, P.C. (2013). Caffeine in floral nectar enhances a pollinator's memory of reward. Science 339, 1202-1204.

Yang, C., Lu, X., Ma, B., Chen, S.Y. \& Zhang, J.S. (2015). Ethylene signaling in rice and Arabidopsis: conserved and diverged aspects. Molecular Plant 8, 495-505.

Yokawa, K. \& Baluška, F. (2015). C. elegans and Arabidopsis thaliana show similar behavior: ROS induce escape tropisms both in illuminated nematodes and roots. Plant Signaling \& Behavior, In Press.

Yokawa, K., Derrien-Maze, N., Mancuso, S. \& Baluška, F. (2014a). Binary decisions in maize root behavior: Y-maze system as tool for unconventional computation in plants. International Journal of Unconventional Computing 10, 381-390.

Yokawa, K., Fassano, R., Kagenishi, T. \& Baluška, F. (2014b). Light as stress factor to plant roots - case of root halotropism. Frontiers in Plant Science 5, 718.

Yokawa, K., Kagenishi, T., Kawano, T., Mancuso, S. \& Baluška, F. (2011). Illumination of Arabidopsis roots induces immediate burst of ROS production. Plant Signaling \& Behavior 6, 1457-1461.

Žárský, V. (2015). GABA receptor found in plants. Nature Plants 1, In press. 